\title{
Nurturing a Sustainable Earth System in the Age of Science and Technology: From Francis Bacon's Conquest of Nature to Albert Schweitzer's Ethics of Reverence for Life
}

\author{
Choy Yee Keong
}

\begin{abstract}
Compelling evidence reveals that exponential growth of human activities as a result of science and technological advancement over the past few decades has been driving planetary change at an unprecedented pace and magnitude. The cumulative anthropogenic environmental pressure threatening human long-term existence calls for urgent and immediate mitigating measures. The challenge here is to raise human environmental awareness based on an empirical assessment of human-driven environmental changes, and to examine the moral causes of environmentally destructive human practices rooted in the Baconian stance of human supremacy over nature. To orient further analysis towards this line of thought, the article attempts to craft a philosophical framework of nature drawing from Albert Schweitzer's reverence for life ethics that will deepen our understanding of human environmental behaviour and ethical engagement with, and stewardship responsibility to, nature. It is concluded that nurturing a sustainable world requires the human race to uphold strong ethical commitment to protect and conserve non-human nature.
\end{abstract}

Index Terms-Albert Schweitzer, biocentrism, conquest of nature, ecocentrism, Francis Bacon, reverence for life ethics.

\section{INTRODUCTION}

What does it mean to be human in the material age of science and technology? Doubtlessly, scientific progress and industrial technological advancement have increasingly become fundamental to modern society. They are recognized as the condiciones sine quibus non for ensuring national prestige and economic progress and advancement of material wellbeing for humanity. They are considered the harbinger for industrial and socio-economic modernity. Remove these two components from our global economic system, and our culture will collapse.

To this end, modern society has deployed science and technology to change and manipulate the world to suit with one another for status and wealth and to serve immediate national interests and individual self-fulfilment. Science and technology have dynamically changed our society and the way we live based on the anthropocentric worldview of progress, in sharp contrast to our long-held ethical values with regard to our natural environment-that it is the fundamental source of our socio-economic well-being in terms of resource input and the various life-support services

Manuscript received April 21, 2017. This work was fully supported by Grant-in-Aid "Scientific Research (C), Ministry of Education, Culture, Sports, Science and Technology, Japan.

Choy Yee Keong is with the Faculty of Economics, Keio University, Tokyo, Japan (e-mail: choy3293@ gmail.com). it provides. Briefly, anthropocentrism is a human-centred philosophical viewpoint that humans are the most significant living entities on earth. Humans are also regarded as separate from and superior to nature.

From this perspective, humans see themselves as a part of the larger global economic system and human conscience is based on a mechanistic worldview of resource maximization for material progress. In a mechanistic worldview, the world is embraced as a non-living machine comprising a collection of objects meant for human consumption, and nature itself is seen as an object of scientific control [1]. The power of science and technology has penetrated deeper and wider into nature to unearth or decimate everything from the Earth system in the name of sustainable socio-economic progress. Humanity has embarked on the "conquest of Nature" and dominance of the Earth system with the resultant impacts of extensive deforestation especially in the tropics, habitat fragmentation, biodiversity depletion and massive green house gases emissions, among others. By destabilizing the human living environment which threatens long-term human survival, man's quest to conquer Nature has become "Nature's conquest of man".

The problem lies in our disregard for ethics. We increasingly see ourselves as separate from nature and we have become a global geological force in our own right capable of controlling, manipulating and exploiting the Earth system to serve human interests. Tensions and conflicts are increasing between the individual pursuit of self-interest and environmental protection. Logically, the challenge here is to make humans move away from anthropocentrism to embrace our Earth system as worthy of moral consideration.

With this view in mind, this article aims to review the evolution of thought in ethical disciplines from two contrasting perspectives: Francis Bacon's conquest of nature and utility maximization philosophy and Albert Schweitzer's reverence for life ethics, and their practical implications for nurturing a sustainable world.

\section{FRANCIS BACON'S PHILOSOPHY AND MODERN CAPITALIST SOCIETY}

It is apparent that the global economy depends significantly on the extraction of raw materials from nature in its production processes, and that the continued existence of humanity hinges on the life-support services such as purification of air and water and regulation of climate provided by our ecosystems. However, for too long since the advent of the Industrial Revolution during the late 1700s and early 1800 s, human beings seem to have held a mechanical 
and instrumental view of the world. As described in Francis Bacon's philosophy of human mastery of nature, in a mechanistic and instrumental world, human beings may view nature as a "non-living machine [comprising] a collection of objects, meant for human consumption, and nature itself was seen as an object of scientific control.", to borrow the words of David Fideler [1] (pp.4-5)

Francis Bacon, in his book, The Great Instauration of the Dominion of Man over the Universe, called for the return of mankind's command over the Garden of Eden (the universe lost by Adam in the Fall) [2]. In the Novum Organon (literally the "New Instrument"), he further implies that, through mechanical arts, scientific progress and technological invention, "Let the human race recover that right over the nature which belongs to it by divine bequest, and let power be given to it" [3] (p. 50 ). According to Bacon, mastery of nature was to be achieved by the application of experimental investigation. Bacon argues that "nature exhibits herself more clearly under the trials and vexations of art than when left to herself [4] (p. 740). Accordingly, Bacon calls upon the "true sons of knowledge" to penetrate further into "the outer courts of nature" and "find a way at length into her inner chamber," [5] (p. 146).

Using the discipline of scientific knowledge, and mechanical inventions, humans could then not "merely exert a gentle guidance over nature's course" but also would be able "to conquer and subdue her, to shake her to her foundations" and to discover "the secrets still locked in nature's bosom" [2] (pp.93-95) [6]. According to Bacon, nature ought to be conquered and turned into the slave of mankind so that it could better serve human interest and comfort [7]. Bacon urged men "to make peace between themselves, and turning with united forces against the Nature of Things, to storm and occupy her castles and strongholds, and extend the bound of human empire" [8] (p. 291). In this way humans would subdue "nature with all her children to bind her to your service and make her your slave" [2] (p.62). This fundamentally established Bacon's philosophy of "Dominion of Man over the Universe" and laid the foundation of "human utility and power" to "subdue and overcome the necessities and miseries of humanity" and improve the life of humankind [9] (pp. 21, 27), [1].

Thus, in Bacon's mechanical view of earth, nature has value as an object of human use for the betterment of life, that is it has only instrumental value, and as an object of technological control and manipulation. Nature does not deserve any special moral consideration or reverence because it is not imbued with intrinsic value. An object is said to be intrinsically valuable when it is valuable in itself or for its own sake. Thus, Mankind is free to technologically shake it to the foundation and instrumentally appropriate it to the fullest extent insofar as it serves to maximize "human utility and power". Technically speaking, the Baconian world is a human-centred world or an anthropocentric universe exhibiting a profound separation between man and Nature. Anthropocentrism is an ethic in which the interests of human beings are central: in the Baconian view of man's dominion over the Universe, human beings are at the centre of the world.

Our modern capitalist society has come to embrace
Bacon's view of the universe and thus treats nature as a servant of wealth maximization. Indeed, what sustains our current capitalist society is precisely the steadfast endorsement and application of the Baconian human-nature-utility philosophy to maximize wealth accumulation at the expense of the environment. In other words, the Baconian human-nature-utility philosophy has turned into a widely accepted guiding principle for development priorities across the planet with the focus on how much humanity can instrumentally subdue nature to better serve human interest and comfort with scant concern for the resultant environmental impacts of our anthropocentric behaviour and exploitative actions. Consequently, human beings are now living in a world of rapid anthropogenic environmental change. This includes the anthropogenically driven environmental degradation, deforestation, habitat destruction, biodiversity loss, and global warming, among others, which have grown in scale and spread.

\section{From HumAN CONQUEST OF NATURE TO NATURE'S CONQUEST OF HUMAN}

Human conquest of nature in the modern capitalist society is well represented by the massive loss of forests and biodiversity. For example, in 2014, the world lost more than 18 million hectares of tree cover, an area twice the size of Portugal. Russia led globally as having the highest forest cover loss followed by Brazil. In addition, based on the Millennium Ecosystem Assessment, roughly 10 to 30 percent of the mammal, bird and amphibian species were threatened with extinction due to human activities [10]. The Global Biodiversity Outlook 4 also reveals that despite individual success stories, the average risk of extinction for birds, mammals and amphibians is still increasing. Also, the genetic diversity of domesticated livestock is eroding. Worse yet, more than one-fifth of the breeds are at risk of extinction while the wild relatives of domesticated crop species are increasingly threatened by habitat fragmentation and climate change [11]. In reinforcing the Millennium Ecosystem Assessment findings, the International Union for Conservation of Nature (IUCN) has revealed that 21 percent of all known mammals, 30 percent of all known amphibians, 12 percent of all known birds, and 28 percent of reptiles, 37 percent of freshwater fishes, 70 percent of plants, 35 percent of invertebrates are at the risk of extinction [12].

The number of the world's dead zones has been doubling in frequency every 10 years since the 1960s, and by 2007 the number had reached around 500. Dead zones are large bodies of water typically in the ocean and occasionally in lakes and rivers with water oxygen levels having dropped to levels too low to support marine or aquatic life. Dead zones are largely caused by nitrogen and phosphorous from agricultural runoff, which is the result of uncontrolled use of chemical fertilizers. In addition, the ocean water has become 30 percent more acidic due to the absorption of carbon dioxide $\left(\mathrm{CO}_{2}\right)$ released by the burning of fossil fuels [13].

Furthermore, our atmospheric sinks continue to be overburdened by massive increase in cumulative $\mathrm{CO}_{2}$ emission, aggravating the global warming problem with its 
resultant impact of massive flooding, heat waves and unseasonal rain and droughts. It is noteworthy that $\mathrm{CO}_{2}$ emissions from the combustion of fossil fuels and cement production have increased by 126 percent from 16.03 billion tonnes in 1972 to 36.26 billion tonnes in 2015 [14].

Thus, the extent of anthropogenic environmental damage is immense and at times, irreversible and destructive. For example, anthropogenic induced global warming which result in deadly heat waves, unseasonal rainfall, acid rain, air pollution, desertification and massive flooding, among others, which has in turn taken a heavy toll on human lives. For example, as reflected below, global warming is playing a critical role in intensifying heat waves that kill many people:

1) The Chicago heat wave of 1999 resulted in at least 80 deaths

2) The 2003 European heat wave killed more than 80,000 people (the deadliest in world history)

3) The 2010 Japanese heat wave that killed 1718 people

4) The Indian heat wave of 2015 with temperatures hit $48{ }^{\circ} \mathrm{C}\left(118^{\circ} \mathrm{F}\right)$ in some cities, killing 2,330 people (5th deadliest in the world history)

5) The Pakistan heat wave of 2015 that killed more than 800 people. [13].

Other anthropogenic induced natural disasters include some of the followings:

1) The Yangtze floods of 1998 in China which caused more than 4,000 deaths

2) The 2010 Pakistan flood which killed more than 1,700 people

3) The Mozambican flood of 2000 which was worsened by two cyclones caused 800 deaths and affected almost 2 million people

4) The heavy flood of 2010 in northwest Pakistan which killed 1,752 people. [13].

In addition, other human induced life-threatening environmental changes which are noteworthy are:

1) The total available water of the African large catchment basins of Niger, Lake Chad and Senega has decreased by 40 to 60 percent

2) The East African drought between 2011 and mid-2012 (claimed to be to the worst drought in 60 years)

3) Annual rainfall, runoff and soil moisture in southern, northern and western Africa have declined leading to increased summer drying and the associated risk of drought

4) Increased evaporation in Australia and New Zealand lead to drier conditions, with a higher probability of drought

5) Decreasing trend of rainfall total as well as its rainfall distribution in Philippines from 1960 to 2010. [13].

The above environmental disasters which are by no means exhaustive are a clear indication of Nature taking revenge on humanity due to our reckless environmental behaviour. Logically, to mitigate the above life-threatening events, it is necessary to reverse the quest of men to conquer nature and reestablish our relationship with nature. The challenge here is to rebuild our conceptual scaffolding to reflect these novel realities and to craft new framework that will open doors for our ethical engagement with nature when optimizing its instrumental use. Here we may turn to Albert Schweitzer who might offer some insights in allowing us to see the same Universe from a different perceptive.

\section{AlbERT SCHWEITZER's ETHICS: REVERENCE FOR LIFE AND PLANETARY STEWARDSHIP}

Albert Schweitzer is one of the earliest and most influential philosophers to bring to the fore a moral argument assigning ethical consideration to all individual living organisms. Central to Schweitzer's ethical concept is "reverence for life" which, unlike Francis Bacon's anthropocentric view of nature, argues that confining ethics to only human beings is a misconception. This is clearly reflected in his claim that the reverence for life ethics "is responsibility without limit towards all that lives" [15] (p. 244). Ethics, or environmental ethics for that matter, is a branch of philosophy that studies moral obligations human beings have towards the natural environment which may be expressed in Schweitzer's words as follows: “ It is good to maintain and encourage life; it is bad to destroy life or to obstruct it" [15] (p. 242).

According to Schweitzer, modern industrial society has distanced itself from a worldview that once connected the goodness of life with the goodness of nature. He further concedes that rapid scientific progress and technological development has severed the ethical connection between industrial society and the natural system by viewing nature as an indifferent, value-free mechanical force governed by physical and mechanical laws [16] (p. 133). Thus, following his "reverence for life" ethics, he seeks to reinstate this human-nature connection for the establishment of stewardship responsibility towards nature. Thus, in stark contrast to Francis Bacon who calls for humans to make peace and stand united to storm and occupy the strongholds of nature, Schweitzer claims that human beings are inextricably a part of nature and any "thoughtless injury to life" is considered as "incompatible with ethics"[15] (p. 244).

According to him, "A man is truly ethical only when he obeys the compulsion to help all life which he is able to assist, and shrinks from injuring anything that lives... Life as such is sacred to him. He tears no leaf from a tree, plucks no flower and takes care to crush no insect" [15] (p. 243).

Unlike Bacon, Schweitzer holds that nature is intrinsically valuable. Thus he claims that, "Standing, as all living beings are, before this dilemma of the will to live, a person is constantly forced to preserve his own life and life in general only at the cost of other life. If he has been touched by the ethics of reverence for life, he injures and destroys life only under a necessity he cannot avoid, and never from thoughtlessness." [17] (p. 236). Distinguishing his own view from Bacon's philosophy of science and power, Schweitzer concedes that, "All of us must strive for a civilization that is not based on the accretion of science and power alone, but which cares most of all for the spiritual and ethical development of the individual and mankind" [17] (p. 152).

Thus, while Bacon speaks the voice of utility to guide the human race to industrial advancement and material progress, Schweitzer sets forth "an innovative moral perspective centred on self-realization, nature-centred spirituality and ethical idealism" to guide humanity towards an ecological 
civilization of human progress based on environmental stewardship [18] (p. 1).

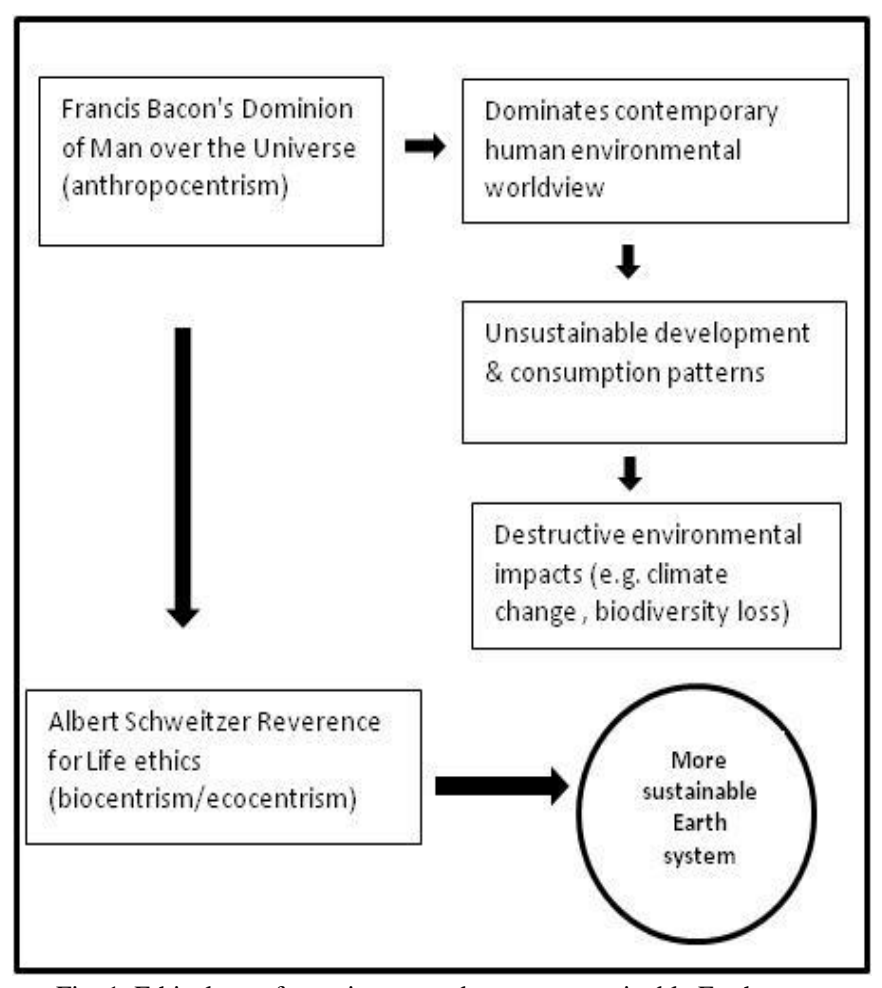

Fig. 1. Ethical transformation towards a more sustainable Earth system. Notes: moving towards this goal of sustainability requires fundamental changes in our attitudes and behaviour based on Schweitzer's reverence for life ethics

It is by now increasingly clear that Schweitzer's ethics of reverence for life is a noble one for it draws and encourages the human race to work together to discard human-centred sentiments, and begin to meet the needs of all including non-human living entities, and to return civilization to its ethical and moral grounds. Indeed, it is not an exaggeration to claim that Schweitzer's reverence for life ethics offers a universally applicable moral framework to bridge the major disconnect between humans and nature. Once we are reconnected to nature based on the ethical principles of the reverence for life, there is a tendency for us to move away from the anthropocentric environmental worldview or the Baconian utility maximization focus towards the biocentric view of life or ecocentric mode of moral concern for nature. Biocentrism refers to the extension of moral or ethical consideration to all individual living things in nature. It rejects the notion of human superiority over other non-human species. It holds that all life in the natural world deserves equal moral consideration or has equal moral standing. Biocentrism is individualistic in that it limits its moral consideration only to individual living organisms [13]. However, ecocentrism, unlike biocentricism, extends moral consideration to a spectrum of non-human environmental entities including species, habitats and the ecosystem. It is a kind of Earth-respecting belief system which allows values to be understood more holistically. These values, which constitute the basis for our ethical reasoning towards nature, influence our environmental behaviour and treatment of nature consciously or unconsciously based on the admission of moral values for non-human entities. However, it may be remarked in light of this that the initial endorsement of biocentrism may probably lead to greater ethical assimilation of ecocentrism as many of their principles overlap.

Schweitzer's reverence for life holds one the major ethical keys to encourage humans to shoulder the ethical responsibly (biocentric or ecocentric) for environmental protection when optimizing its economic use through sustainable development practices and lifestyles as well as to practise restraint in our production and consumption habits. Indeed, as has been argued extensively elsewhere drawing from evidence from field research, there is an inextricable link between moral concern for nature and environmental protection [19]-[21].

\section{CONCLUSION}

We are living in a Baconian world of utility maximization driven by the never-ending capitalist or individual pursuit for economic growth, material progress and welfare maximization. Undoubtedly, science and technology has given humanity the power to penetrate deeper and wider into our Earth system for all the resources available to enhance and sustain this socio-economic flourishing with little regard for the impact of our actions. In the race for greater material advancement, humanity has become increasingly disconnected from the natural world, treating nature instrumentally as a means for the enhancement of long-term socio-economic prosperity. This opens the gateway for massive exploitation of our Earth system leading to a host of environmental problems which affect the core of human long-term existence.

Human assault on the environment is so intense it has taken a heavy toll on human lives in the form of extreme environmental weather conditions such as massive flooding and deadly heat waves. This is an urgent call for putting in place an ethical system that prioritizes long-term and planetary health. As shown in Fig. 1, moving towards this goal of sustainability requires fundamental changes in our attitudes and behaviour based on Schweitzer's reverence for life ethics which may encourage us to move from anthropocentrism to biocentrism or ecocentrism.

Undoubtedly, the only possible path towards mitigating the current environmental problems facing us today is by embracing an ethic built on preserving and sustaining the earth's system of living things, and Schweitzer shows just the way. Given the prevailing dire global environmental scenario, humanity needs to ethically and morally commit to undertake precautionary steward measures to reverse our environmental decline. It is time for us to embrace Schweitzer's advice: "The time is coming, however, when people will be astonished that mankind needed so long a time to learn to regard thoughtless injury to life as incompatible with ethics" [15] (p. 244), and to take heed of his warning unveiled in the 1950s that: if "Man has lost the capacity to foresee and forestall...He will end up destroying the earth" [22] (p.1132).

\section{ACKNOWLEDGMENT}

The author would like to thank the three anonymous reviewers for their constructive comments. 


\section{REFERENCES}

[1] D. Fideler, Restoring the Soul of the World: Our Living Bond with Nature's Intelligence, Rochester, Vermont: Inner Traditions, 2014

[2] F. Bacon, "The masculine birth of time, or the great instauration of the dominion of man over the universe," The Philosophy of Francis Bacon: An Essay on its Development from 1603 to 1609, UK: Liverpool University Press, 1964, pp. 59-62.

[3] W. Leiss, The Domination of Nature, Montreal \& Kingston, London, Buffalo: McGill-Queen University Press, 1994.

[4] C. Merchant, "The violence of impediments. Francis Bacon and the origins of experimentation," The History of Science Society, vol. 99, pp. 731-760, 2008.

[5] F. Bacon, "Preface to the novum organum," Preface and Prologues to Famous Book, The Harvard Classics, USA: P.F Collier \& Son Corporation, pp. 143-147, 1901.

[6] F. Bacon, The New Organon or: True Directions Concerning the Interpretation of Nature, Copyright @2010-2015, Jonathan Bennett, 2007.

[7] Z. Bauman, Work, Consumerism and the New Poor, England: Open University Press, 2005.

[8] M. Peltonen, "Politics and science: Francis Bacon and the true greatness of states," The Historical Journal, vol. 35, no. 2, pp. 279-305, 1992.

[9] F. Bacon, The Works of Francis Bacon. Volume 4: Translations of the Philosophical Works, Cambridge. New York: Cambridge University Press, 2011.

[10] MEA, "Ecosystems and human well-being: Synthesis," Millennium Ecosystem Assessment (MEA), Washington, DC: Island Press, 2005.

[11] Secretariat of the Convention on Biological Diversity, Global Biodiversity Outlook 4. A Mid-term Assessment towards the Implementation of the Strategic Plan for Biodiversity 2011-2020, Montreal: Secretariat of the Convention on Biological Diversity.

[12] C. Hilton-Taylor, C. M. Pollock, C, J. S. Chanson, Stuart H. M. Butchart, Thomasina E. E. Oldfield, and V. Katariya, "State of the world's species," Wildlife in a Changing World. An analysis of the 2008 IUCN Red List of Threatened Species, Gland, Switzerland: International Union for Conservation of Nature and Natural Resource (ICUN), 2009, pp. 12-41.

[13] Y. K. Choy, "Ecosystem health, human existence, and bio-capacity deficit: The ethical relationship." International Journal of Sustainable Development and Planning, vol. 11, no. 6, pp. 1004-1016, 2016.
[14] T. A. Boden, G. A. Marland, and R. J. Andres, Global, Regional, and National Fossil-Fuel $\mathrm{CO}_{2}$ Emissions, Oak Ridge, Tenn., U.S.A: Carbon Dioxide Information Analysis Center, Oak Ridge National Laboratory, U.S. Department of Energy, 2016.

[15] A. Schweitzer, The Philosophy of Civilization. Civilization and Ethics, London: Adam \& Charles Black, 1949.

[16] J. R. Jardins, Environmental Ethics. An Introduction to Environmental Philosophy, Boston, USA: Wadsworth Cengage Learning, 2013.

[17] A. Schweitzer, Out of My Life and Thought, $60^{\text {th }}$ Anniversary Edition, Baltimore, Maryland: Johns Hopkins University Press, 2009.

[18] M. W. Martin, Albert Schweitzer's Reverence for Life: Ethical Idealism and Self-realization, Hampshire, England, Burlington, USA: Ashgate Publishing Limited, 2007.

[19] Y. K. Choy, "Land ethic from the Borneo tropical rainforests in Sarawak, Malaysia: An empirical and conceptual analysis," Environmental Ethics, issue 4, pp. 421-441, 2014.

[20] Y. K. Choy, "From Stockholm to Rio+20: The ASEAN environmental paradox, environmental sustainability and environmental ethics," The International Journal of Environmental Sustainability, vol. 12, no.1, pp. 1-25, 2015.

[21] Y. K. Choy, "Sustainable development: The nexus of environmental sustainability, values and ethics," European Journal of Sustainable Development, vol. 6, no. 1, pp. 308-324, 2017.

[22] R. Harris, "Schweitzer and Africa," The Historical Journal, vol. 59, no. 4, pp. 1107-1132, 2016.

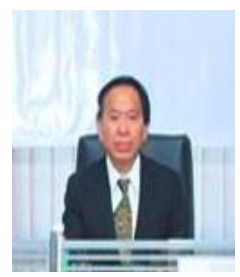

Choy Yee Keong is a graduate of the Institute of Chartered Secretaries and Administrators, United Kingdom. He received his master of economics from Chuo University, Tokyo, Japan, majoring in development economics, and the doctor of philosophy in economics from Keio University, Tokyo, Japan, majoring in development and environmental economics. His research interests primarily focus on various aspects of sustainable development, environmental conservation and environmental ethics. He has more than 10 years of field research experience on various policy-oriented development and environmental research activities in Malaysia. 